\title{
Relationship between Activity Noise, Voice Parameters, and Voice Symptoms among Female Teachers
}

\author{
Sirpa Pirilä,Paula Pirilä,Terhi Ansamaa,Anneli Yliherva,Samuel Sonning, Leena \\ Rantala
}

\begin{abstract}
Objective: Our interest was in how teachers' voices behave during the delivery of lessons in core subjects (e.g., mathematics, science, etc.). We sought to evaluate the relationship between voice sound pressure level (SPL), vocal fundamental frequency $\left(F_{0}\right)$, voice symptoms, activity noise, and differences therein during the first and the last lessons in core subjects of the day. Patients and Methods: The participants were 24 female elementary school teachers. Voice symptoms were evaluated by questionnaire. The data were recorded on 2 portable voice accumulators (VoxLog) from the first and last lessons of the day. The versions of accumulators differed by frequency weighting; therefore, the analysis and the results of noise and voice SPL were treated separately: unweighted (group 1) and A-weighted (group 2). Results: Difference in voice SPL followed difference in activity noise. Fo increased between the first and last lessons. Correlations were found between differences in the noise and the voice symptoms of tiredness and dryness. Irritating mucus was associated with high $F_{0}$ during the first lesson. Conclusion: An apparent increase in voice loading due to the activity noise was observed during lessons in core subjects. Collaboration between specialists in voice and acoustics and teachers and pupils is needed to reduce this voice loading.
\end{abstract}

\section{Introduction}

Research has shown consistently that elementary school classrooms are a noisy environment [1--3]. Noise during the delivery of lessons consists mainly of children's and teachers' talking and activities, such as moving furniture, handling materials, and noise from devices used in teaching. In recent studies this kind of noise and its effects have been investigated separately from background noise and are referred to as activity noise $[1,4]$. Although activity noise is not continuous in the same way as background noise, teachers' voices 
nevertheless react to it. Teachers have been found to use a raised voice in $61 \%$ of their lessons [2]. Voice symptoms and poor voice quality complicate teaching and may oblige a teacher to take sick leave $[5,6]$. Furthermore, pupils react to a teacher's dysphonic voice, which may have a detrimental effect on their academic performance [7].

Activity noise levels may vary depending on the school subject. Music and sports lessons include intermittent loud sounds and, consequently, the activity noise level during these lessons has been studied most $[2,8,9]$. Less attention has been paid to the connection between the sound environment and teachers' voice use during lessons in core subjects (mathematics, languages, history, geography, and science). Lessons in core subjects, however, may be no exception in terms of the presence of loud sounds. The noise level may vary by $20 \mathrm{~dB}$ depending on the activities during the lesson, as Shield and Dockrell [3] have reported. In their study they found an average noise level of $56 \mathrm{dBA}$ during individual silent work and $73 \mathrm{dBA}$ during group work.

A speaker reacts to a noisy or loud environment unconsciously by changing her voice behaviour, a phenomenon called the Lombard effect [10]. In a laboratory setting, a common reaction for a vocally healthy speaker is to elevate the sound pressure level (SPL) and fundamental frequency $\left(F_{0}\right)$ in response to an increased noise level $[11,12]$. However, in reallife scenarios, such as in kindergarten environments [13], the relationship between noise and voice level is not always as straightforward as in the laboratory setting. Evidence suggests that the voices of speakers with and without voice disorders behave somewhat differently when under load. Teachers with voice symptoms use lower voice SPL and Fo during their work than their vocally healthy peers [14], and $F_{0}$ does not rise in teachers with voice symptoms as it does in almost vocally healthy teachers [15]. These findings regarding the differences between teachers with and without voice disorders suggest a need to study how teachers with voice symptoms behave vocally under work-related loading in real-life scenarios. 
Our interest in the present research was to study how teachers' voices behave during the delivery of lessons in core subjects. In addition, our participants had several voice symptoms and, hence, might react differently to noise than teachers without those symptoms. We aimed to identify relationships between the activity noise level and a teacher's voice SPL and Fo. We also studied whether the activity noise level, voice SPL, and $F_{0}$ changed during a working day and whether the changes correlated with each other.

\section{Methods}

\section{Participants}

Twenty-four female teachers (median age 41 years, range 27-63 years) from 21 elementary schools in the area of Oulu and nearby municipalities were recruited for participation. Seventeen of the participants were regular classroom teachers and 7 were special education teachers. The head teachers of the schools were informed about the study and asked to pass the recruitment information on to their female teachers. The inclusion criteria for the participants were as follows: voice symptoms and willingness to participate in voice therapy, mother tongue Finnish, no hearing loss, non-smoking, no neurological diseases, no voice therapy during the past year, successful phoniatric examination with rigid laryngoscopy or nasal endoscopy. Thirteen (54\%) teachers suffered from allergic rhinitis and/or asthma and 5 of them had an asthma medication. Eight (33\%) reported experiencing flu-like symptoms 4 times a year or more. The average number of years of working experience was 15 (range 3-30 years). The total number of children were 350 and the average number of children during a lesson was 15 (range 5--28). The children were enrolled from the first to the fifth grades of and ranged in age from 6 to 13 years.

The participants' voice symptoms were evaluated with a questionnaire eliciting the most typical voice symptoms on the basis of the literature [15]. Our questionnaire was a slightly 
modified version of the voice screening method by Simberg et al. [16], which has been found to effectively distinguish a normal from an abnormal voice. The distribution of the participants' voice symptoms is shown in Table 1. The scores from the voice questionnaire were summarized on a 4-point scale ( 1 point $=$ less than once a year or never, 2 points $=$ a couple of times each year or occasionally, 3 points $=$ about once a month or quite often, 4 points $=$ almost every week or very often).

\section{Phoniatric Examination}

Phoniatric examination was made with a videolaryngostroboscopy (VLS) system and/or a nasopharyngofiberoscope. The VLS system (Rp-Szene version 6.2, Rehder/Partner GmbH, Germany) consisted of a frequency analyzer (MEZ-2/T), a strobe light source (KS-4200), a camera (rpCam250P) combined with a 70-degree rigid laryngeal endoscope (model 4450.501, Richard Wolf and/or model 8706CA, Karl Storz). Recordings were made in digital format on a personal computer (with RP-Szene software). During the examination the participants sat leaning forward with their chins elevated. The recordings with the rigid endoscopy were performed during vocal production of an intermittent [e] and sustained [e:], during a glissando, and also during a reading task with the nasoendoscopy. All of the examinations and analyses were conducted by an experienced phoniatrician.

According to the VLS examination, 6 (25\%) of the teachers were classified as healthy, 15 (62.5\%) had some minor laryngeal findings (mild vocal fold erythema, mild arythenoid edema, excessive mucus, supraglottic lateral or anterioposterior contraction and/or some closure incompetence) and $3(12.5 \%)$ of the participants had organic findings (vocal fold nodules, a small vocal fold polyp, a capillary ectasia of the vocal fold, presbyphonia/vocal fold atrophy).

Recordings and Variables 
The participants recorded their voice using a portable voice accumulator (VoxLog, Sonvox AB, Sweden) (Fig. 1) that was fastened with a clip to a waistband. A miniature accelerometer and small microphone were placed in a neck collar that was connected to the voice accumulator unit. The recordings were made throughout the working day, and the data from the first and last lessons in core subjects were taken for analysis. The first lesson in core subjects began between 8.03 and 10.00 a.m. and the last began between 11.15 a.m. and 13.30 p.m. The average length of a lesson was $45 \mathrm{~min}$. There was an average of $3 \mathrm{~h}$ (range $2-4 \mathrm{~h}$ ) between the first and last lessons in core subjects. The participants were given both oral and written instructions for the recordings. The collar size could be adjusted to suit each teacher to avoid moving it, as discussed by Whitling et al. [17]. Teachers reported in diaries the subjects taught in the lessons as well as exceptional events or voice problems. Four teachers also taught music or gymnastics during the recording day, while the rest taught only lessons in core subjects.

Variables measured with the portable voice accumulator were noise level, voice SPL, and $\mathrm{F}_{0_{-}}$The accelerometer detects and estimates the skin acceleration caused by vocal fold vibration for measures of $F_{0}(H z)$ and the microphone measures voice SPL $(d B)$ (when a subject is voicing) and noise level (when a subject is not voicing). Because the acoustic speech signal is not recorded, the privacy of the speaker is secured. The voice accumulator uses a variable time window length, which in this study was set at $1 \mathrm{~min}$, meaning that each SPL sample is an equivalent continuous sound level over a time period of 1 min. Crucially, in the case of varying SPL, this value is not the same as the arithmetic mean of several SPL values of shorter window length, e.g. 100 ms. For noise measurements, the registered sound level was taken as is, without calibration, as the ambient noise level should be similar between nearby positions (between the position of the collar and the ears of the subject), since most noise is expected to 
be generated much farther away from the participant than the distance between the collar and the ears of the participant.

\section{Analysis}

For the analysis of the noise level and voice SPL, participants were divided into 2 groups

(groups 1 and 2). This was because the data were collected with two voice accumulators (procured at different times) that measured sound levels with different frequency weighting: unweighted (dB; the very first version of the device; group 1) and A-weighted (dBA; the newer version of the device; group 2). There were 18 participants in group 1 and 6 in group 2 . The difference in weighting was not identified until all the data were recorded. Although the weighting affects sound levels, we decided to report the results given by the two versions of voice accumulators. For speech, the unweighted and A-weighted levels were fairly close to each other, the A-weighted level typically being 3-4 dB lower for normal speech but only 0-1 dB lower for loud speech or shouting [18]. For environmental noise, however, unweighted and Aweighted levels may differ greatly due to the possibility of the presence of low-frequency noise.

\section{Statistical Analyses}

The statistical analyses were carried out with SPSS software (IBM SPSS Statistics v. 22, Armonk, NY, USA). Medians were used because of the non-normal distribution of the voice SPL and $\mathrm{F}_{0}$ (Shapiro-Wilk test). To calculate the medians of the first and last lessons, we first took the median of each teacher's voice and noise levels and Fo measurements of the 1-min frames from the voice accumulator. Second, we determined the median of these median values as representative of the data at the group level. The correlations between the variables were studied with Spearman's rank-order correlation (rho). Differences between the variables in the first and last lessons were analysed by the Wilcoxon signed-rank test. 


\section{Results}

Activity Noise Levels and Teachers' Voice SPL and Fo

The median of the activity noise levels in group 1 was $78 \mathrm{~dB}$ during the first and last lessons in core subjects and the medians of the noise levels in group 2 were $60 \mathrm{dBA}$ during the first and 63 dBA during the last lesson in a core subject (Table 2). The medians and maxima of the noise level measurements of each classroom are presented in Figure $2 a$ and b. Although there were no statistically significant differences $(z=-1.519, p=0.129)$ at the group level in the activity noise, the noise levels sometimes increased and decreased during lessons: from the first lesson to the last lesson, the noise level rose 1-10 dB in 13 classrooms, decreased 1-5 dB in 7, and remained unchanged in 4 classrooms (Fig. 3).

During the first lesson, the median for voice SPL in group 1 was $82 \mathrm{~dB}$, corresponding to $\sim 62 \mathrm{~dB}($ at $1 \mathrm{~m})$ (ISO 9921-1, 1996) [19], and during the last lesson $81 \mathrm{~dB}$, corresponding to -61 dB (at $1 \mathrm{~m}$ ) (Table 2). In group 2 the median for voice SPL during the first lesson was 85 $\mathrm{dBA}$, corresponding to $\sim 65 \mathrm{~dB}$ (at $1 \mathrm{~m}$ ), and during the last lesson $86 \mathrm{dBA}$, corresponding to $\sim 66 \mathrm{~dB}($ at $1 \mathrm{~m})$. The voice SPL difference reflected the difference in noise level: although there were no statistically significant differences $(z=-1.730, p=0.084)$ at the group level, individual participants' voice SPLs varied. In 11 teachers voice SPL increased by $1-9 \mathrm{~dB}$, in 7 teachers it decreased by $1-3 \mathrm{~dB}$, and in 6 teachers the median value remained unchanged.

Median Fo of all the teachers $(n=24)$ was $201 \mathrm{~Hz}$ during the first and $206 \mathrm{~Hz}$ during the last lesson (range 151-256 and 163-260 Hz, respectively). The rise was statistically significant $(z=3.53, p=0.000)$. From the $F_{0}$ medians for each teacher during the first lesson, low $F_{0}$ values $(<180 \mathrm{~Hz})$ were detected in 6 teachers and high $\mathrm{F}_{0}$ values $(>240 \mathrm{~Hz})$ in 2 teachers. During the last lesson only 3 of the teachers used an Fo lower than $180 \mathrm{~Hz}$, whereas values higher than $240 \mathrm{~Hz}$ were detected in 5 teachers. 


\section{Correlations between Activity Noise Levels and Voice Variables}

In group 1 there was a strong correlation between activity noise level and voice SPL (rho $=0.90, p=0.000$ for the first lesson and rho $=0.85, p=0.000$ for the last one). There was also a slight tendency for voice SPL to increase with increasing noise level in group 2, but because of the small number of participants in this group the correlation was not calculated. The change in the activity noise levels between the first and the last lesson and the change in the teachers' voice SPLs correlated strongly in group 1 (rho $=0.75, p=0.000$ ). The more the activity noise levels increased during teaching, the more the teachers' SPLs rose. In the last lesson, $F_{0}$ of group 1 correlated with noise level $($ rho $=0.57, p=0.014)$.

\section{Correlations with Voice Symptoms}

The change in noise level during teaching correlated with the symptom "My throat feels dry after a long period of talking" (rho $=0.5, p=0.006$ ). The change in noise level also correlated with the symptom "My voice gets tired after a long period of talking" at a significance level slightly over 0.05 (rho $=0.33, p=0.058$ ). The voice symptom "I feel irritating mucus in my throat" correlated during the first lesson with voice $F_{0}$ : the more mucus in the participant's throat, the higher the $\mathrm{F}_{0}$ she used (rho $\left.=0.39, p=0.031\right)$.

\section{Discussion}

The results of our study revealed that during the delivery of lessons in core subjects, teachers' Fo increased and the activity noise levels had an impact on their voices. Previously, it has been shown that loud sounds in music and sports lessons [2, 8, 9] affect teachers' voices. According to our study the loudness of a teacher's voice was associated with the activity noise level during the first and the last lessons in core subjects. The higher the activity noise level in a 
classroom was, the louder was the voice a teacher used. Some correlations between the presence of voice symptoms and the change in noise level and voice pitch were also seen.

\section{Activity Noise}

Since A-weighted measuring is generally used in studies on activity noise levels, the Aweighted values of the present study were used when comparing the results with those of earlier studies. However, we found no studies with exactly the same study design. There were 2 studies analysing noise levels during lessons in core subjects, namely Kristiansen et al. [2] and Cantor Cutiva et al. [20]. Our results were approximately $10 \mathrm{~dB}$ lower than those reported by Kristiansen et al. [2] measured by a personal dosimeter, and $4 \mathrm{~dB}$ higher than those reported by Cantor Cutiva et al. [20] measured with a noise level meter. The differences may be attributable to differences in measuring methods. Our voice accumulator registered the noise levels every minute, whereas in the study by Kristiansen et al. the noise levels were recorded every second and in the study by Cantor Cutiva et al., the noise level was estimated as the 90th percentile level, which describes the level that was exceeded for $90 \%$ of the measurement period. It is also possible that the difference was caused by the location of the device. In the study by Cantor Cutiva et al. the sound level meter was located firmly close to the teacher's desk. In our study the voice accumulator was fastened with a clip on the teacher's waistband and so it was "travelling" around in the classroom with the teacher. Because teachers and children were likely to move about in the classroom, varying distances between the microphone and the noise source might occur causing differences in the noise level results. Furthermore, because past studies have been made in different countries, it is possible that the potential variation in the activities during lessons may have caused the differences [3], even though all these studies were concerned with lessons in core subjects. In light of earlier findings [21] that the noise levels in the classroom tend to decrease as the children's ages increase, it seems unlikely that the difference could be explained by the older pupils in the study by Kristiansen et al. [2]. 
To the best of our knowledge, only 2 research groups, Echternach et al. [22] and Södersten et al. [23], used an accelerometer (VoxLog) similar to ours for activity noise level measurement during teaching. Both studies report $9 \mathrm{~dB}$ higher values for activity noise level than the present study. The explanation for the different results may be that in those 2 studies all lessons were recorded, not specifically lessons in core subjects and, furthermore, leisure time was also included in most of the recordings by Södersten et al. Other possible reasons for the differences may be variation in pedagogical methods [24], in the subjects addressed in the lessons [2], or in the acoustics of the classroom [25]. Furthermore, variations in time window settings may have also influenced the differences. We used a 1-min time window, as did Södersten et al. [23], whereas Echternach et al. [22] used a 5-s time window. Possible variation in statistical methods could explain some of the differences: we used medians, while Södersten et al. and Echternach et al. used means.

In the present study the median activity noise level did not change during the first and last lessons in core subjects. However, individual variation was quite large in the classroom noise levels. In over half of the classrooms, the activity noise level rose and the greatest increase was as high as $10 \mathrm{~dB}$. Although the teachers reported "basic teaching" in their diaries, it is possible that different activities took place in the classrooms, which may account for the wide variation in the noise levels as Shield and Dockrell [3] have reported. Skarlatos and Manatakis [26] and Sarantopoulos et al. [27] propose another plausible explanation for the rise in noise during the afternoon lesson in a core subject. These researchers suggest that the noise may originate from the possible fatigue and associated restlessness of children towards the end of the school day. This is a credible assumption, because in our study lessons in core subjects were only given during the recording days in 20 out of 24 classrooms. In four classrooms music or gymnastics were also provided. 
The difference between the speech level and the noise level (signal-to-noise ratio, SNR) [28] with A-weighted measuring was at an acceptable level, $+15 \mathrm{~dB}$ [29], in 5 out of 6 classrooms during the first lesson and in all 6 classrooms during the last lesson (based on the estimated sound level $1 \mathrm{~m}$ in front of the teacher). Such a good speech-to-noise ratio during these lessons revealed a dilemma: from the children's point of view, this finding was desirable and indicated that the voice of teacher was easily heard in the classroom (although the SNR may be worse at the students' position, since the teacher's sound level will likely be lower there) but, from the teacher's point of view, the finding revealed raised voice use. It seemed possible that the teachers may adjust their voice to increase SNR at the listener's position rather than at their own position and preferred to use their voice as required by their profession instead of more ergonomically [23]. A possible solution to this dilemma might be a compromise between a good listening acoustic [25] and a good speaking acoustic [30] environment. Although the comparison between a speech-to-noise and an SNR is simplistic because the ratios are not truly the same, the juxtaposition signals an alarming situation: in order to be heard a teacher had to use a raised voice. Furthermore, it may be demanding to find simple solutions to the problem. They seem to include either risks (must a teacher increase the loudness of her voice?) or notable challenges (how do pupils reduce the noise if the pedagogical approach involves active and participatory class work?) [31--33].

It should be noted that the voice accumulator used in our study treats all sound as noise when the participant is not voicing. For example, any activity noise such as other people talking is registered as noise. Thus we cannot be sure that the noise level registered by the voice accumulator is the same as the noise level during the teacher's speech. In the case of background noise such as traffic, fans, etc., it would most likely stay the same when the individual is speaking. However, in the case of activity noise such as children talking to each other or playing, this noise may well be less during the teacher's speech (since the children may 
become quieter in order to listen to the teacher). Because of this, SNR values derived from taking the noise between speech segments and the voice level during speech segments may be underestimated in the case of activity noise. Also, it should be noted that the SNR at the location of the students will probably be worse than measured by the voice accumulator, since the noise level is likely to be at least as high, while the sound level of the teacher's voice will in most cases be lower than the value $1 \mathrm{~m}$ in front of the mouth.

\section{Voice Loudness and Its Correlation with Activity Noise}

The result of the present study showed that only $25 \%$ (6 of the 24 teachers) exhibited a normal voice SPL of $80 \mathrm{~dB}($ at $0.1 \mathrm{~m}$ ) or lower. The same proportion of teachers talked with raised voice levels, $\geq 86 \mathrm{~dB}$ (at $0.1 \mathrm{~m}$ ), and no teacher used a relaxed level $\leq 74 \mathrm{~dB}$ (at $0.1 \mathrm{~m}$ ). There have so far been no reliable reference values, especially for voice SPL recorded by means of a portable voice accumulator, although some data $[22,23]$ have been published. This study confirms the correlation between noise levels and voice loudness (voice SPL) as shown in both the laboratory environment [12] and field investigations [22]. Our results also showed that the change in voice loudness followed the change in the activity noise levels and that the majority of the teachers increased the loudness of their voices up to $9 \mathrm{~dB}$ apace with the increasing noise level. However, there were some individual reactions to be seen as well: 2 of the teachers decreased the loudness of their voices and 2 of them retained it unchanged. These reactions could be conscious coping strategies under noise [4], which have also been found in kindergarten teachers by Lindström et al. [13].

\section{Voice Pitch and Its Correlation with Activity Noise}

The voice $F_{0}$ values of the present study were similar to those reported in Södersten et al. [23] but somewhat lower than those reported in Lyberg Åhlander et al. [14] and in Rantala et al. [15]. There was a systematic although not large $(5 \mathrm{~Hz})$ increase in $F_{0}$ in the teachers from the 
first to the last lesson. An increase in $F_{0}$ is a typical consequence of vocal loading found both in laboratory settings [34] and in school environments $[15,35]$. In a laboratory setting, $F_{0}$ has been reported to increase in individuals with [36] and without [34] voice problems. There are some differing views concerning the nature of the rise of $\mathrm{F}_{0}$. For example, is it a result of adaptation to vocal load or a sign of vocal fatigue $[15,35,37]$ ? In our study the increase in Fo was probably caused by vocal loading. This is supported by the findings of teachers' feelings of tiredness in the throat after a long period of talking.

The $F_{0}$ values of some teachers were exceptionally low $(151-171 \mathrm{~Hz})$. Because the voice accumulator does not yield acoustic data, we analysed post hoc those participants' spontaneous speech samples recorded with an audio recorder $(\mathrm{Zoom} \mathrm{H2})$ outside of the classroom. A 3-min voice sample was obtained in regard to the teacher's answer to the question: "How is your voice?" The analysis (made with Praat [38]) showed that all teachers had vocal fry ranging from 16 to $54 \%$ in their speech. The presence of vocal fry was examined audibly and visually from the $F_{0}$ curve. It is possible that these teachers also used vocal fry in their teaching speech. This suggestion is supported by the results of Oliveira et al. [39], who showed that vocal fry is a typical feature in the speech of even vocally healthy women of different ages and may occur in all sentence positions. Consistent use of glottal fry may lead to increased tension in phonation with louder voice usage [40]. Thus our results regarding the amount of vocal fry are worrying and may also suggest a new habit of voice use among Finnish women.

\section{Voice Symptoms and Correlations}

The more the noise level in a classroom increased between the first and last lessons, the more often a teacher experienced voice symptoms of dryness and of tiredness. These voice symptoms did not correlate with the voice variables, voice $\mathrm{SPL}$, and $\mathrm{F}_{0}$ but were related to activity noise. Kristiansen et al. [2] also found that voice symptoms correlated more strongly with 
noise levels than with voice SPLs. Our finding gains support from studies showing that there is not always a direct connection between voice SPL and $F_{0}$ and voice symptoms [35, 41]. It is possible that teachers with more severe voice symptoms limit their voice use more than teachers with healthier voices. This is achieved by using lower voice SPL [25] and less raising of $F_{0}[15]$. Our results showed that the more mucus there was in the participant's throat, the higher $F_{0}$ she used during the first lesson. The presence of mucus in the vocal folds may affect the vibratory features of the vocal folds [42] and to compensate for this, it is possible that the teachers in our study used a more strained voice and, hence, raised the pitch [43] in the morning. We could speculate that during the day the consistency of the mucus in the larynx and vocal folds became more influential, for example, due to water ingestion [44] and therefore it did not alter the vibration of the vocal folds as much in the afternoon. Six out of the 9 teachers, who had a significant amount of thick mucus on their vocal folds in the phoniatric examination, also suffered from the symptom of irritating mucus in the throat quite often or very often. Three of the 9 teachers were suffering from allergic rhinitis and/or asthma. Bonilha et al. [45] also found that participants with voice disorders have thicker mucus aggregation and a greater amount of mucus than do vocally healthy individuals.

\section{Methodological Considerations}

It is possible that the present results were affected by the use of the different versions of the portable voice accumulators. The values of the voice SPL and Fo may have been affected to some extent by the possible movement of the collar of a device, as was the case in the study by

Whitling et al. [17], even though in our research the collar was fitted individually for each teacher. The use of the collar itself may have somewhat affected a teacher's voice production. Though the teachers kept diaries of the recording days, there may have been some inaccuracy in notations, which could have affected the results. We could speculate that the results may have been affected to some extent by the children's possible change in behaviour when seeing 
their teacher wearing the portable device as Lyberg Åhlander et al. [14] have also suggested. Lastly, our sample was small, which may limit the generalisability of the results.

\section{Conclusions and Practical Implications}

According to the results of the present study, activity noise had a loading impact on female teachers' voices during the delivery of lessons in core subjects. The difference in voice loudness (SPL) followed differences in the activity noise levels, although some individual reactions were also seen. In addition, $F_{0}$ increased from the first to the last lesson. Correlations were found between differences in noise level and voice symptoms of tiredness and dryness in the throat after talking. Furthermore, the higher a teacher's Fo during the first lesson, the more often she experienced irritating mucus in her throat. Improving the condition of teachers' voices necessitates decreasing the activity noise during lessons. Collaboration between specialists in voice and acoustics and teachers and pupils would contribute to creating a vocally healthy speaking culture in the classroom.

\section{Acknowledgements}

We would like to thank the participants for their kind co-operation, Fredric Lindström, $\mathrm{PhD}$, and Jaana Jokitulppo, PhD, for their help with the study, Prof. Paavo Alku and Prof. Matthias Echternach for their valuable information, and Mrs. Virginia Mattila, MA, for correcting the language of the manuscript.

\section{Statement of Ethics}

The study was duly approved by the Regional Ethics Committee of the Northern Ostrobothnia Hospital District and by the Education and Culture Authority of the City of Oulu. 


\section{Disclosure Statement}

S.P., P.P., T.A., A.Y., and L.R. have no conflicts of interest.

S.S. is responsible for research and development at Sonvox $A B$ and receives financial support from them. Sonvox AB markets the product VoxLog, a collar-based voice accumulator. There are no other relationships or activities that could be seen to have influenced the submitted work.

\section{References}

1 Sala E, Rantala L: Acoustics and activity noise in school classrooms in Finland. Appl Acoust 2016;114:252--259.

2 Kristiansen J, Lund SP, Persson R, Shibuya H, Nielsen PM, Scholz M: A study of classroom acoustics and school teachers' noise exposure, voice load and speaking time during teaching, and the effects on vocal and mental fatigue development. Int Arch Occup Environ Health 2014;87:851--860.

3 Shield B, Dockrell JE: External and internal noise surveys of London primary schools. J Acoust Soc Am 2004;115:730--738. 
4 Rantala LM, Hakala S, Holmqvist S, Sala E: Classroom noise and teachers' voice production. J Speech Lang Hear Res 2015;58:1397--1406.

5 Smolander S, Huttunen K: Voice problems experienced by Finnish comprehensive school teachers and realization of occupational health care. Logoped Phoniatr Vocol 2006;31:166--171.

6 Mattiske JA, Oates JM, Greenwood KM: Vocal problems among teachers: a review of prevalence, causes, prevention, and treatment. J Voice 1998;12:489--499.

7 Lyberg Åhlander V, Haake M, Brannstrom J, Schotz S, Sahlen B: Does the speaker's voice quality influence children's performance on a language comprehension test? Int J Speech Lang Pathol 2015;17:63--73.

8 Schmidt P, Morrow SL: Hoarse with no name: chronic voice problems, policy and music teacher marginalisation. Music Educ Res 2016;18:109--126.

9 Behar A, MacDonald E, Lee J, Cui J, Kunov H, Wong W: Noise exposure of music teachers. J Occup Environ Hyg 2004;1:243--247.

10 Lane $\mathrm{H}$, Tranel B: The Lombard sign and the role of hearing in speech. J Speech Lang Hear Res 1971;14:677--709.

11 Ternström S, Södersten M, Bohman M: Cancellation of simulated environmental noise as a tool for measuring vocal performance during noise exposure. J Voice 2002;16:195--206.

12 Södersten M, Ternström S, Bohman M: Loud speech in realistic environmental noise: phonetogram data, perceptual voice quality, subjective ratings, and gender differences in healthy speakers. J Voice 2005;19:29--46.

13 Lindström F, Waye KP, Södersten M, McAllister A, Ternström S: Observations of the relationship between noise exposure and preschool teacher voice usage in day-care center environments. J Voice 2011;25:166--172. 
14 Lyberg Åhlander V, Pelegrín García D, Whitling S, Rydell R, Löfqvist A: Teachers' voice use in teaching environments: a field study using ambulatory phonation monitor. J Voice 2014;28:841.e5--e15.

15 Rantala L, Vilkman E, Bloigu R: Voice changes during work: subjective complaints and objective measurements for female primary and secondary schoolteachers. J Voice 2002;16:344--355.

16 Simberg S, Sala E, Laine A, Rönnemaa A: A fast and easy screening method for voice disorders among teacher students. Logoped Phoniatr Vocol 2001;26:10--16.

17 Whitling S, Rydell R, Lyberg Åhlander V: Design of a clinical vocal loading test with longtime measurement of voice. J Voice 2015;29:261.e13--e27.

18 Olsen WO: Average speech levels and spectra in various speaking/listening conditions. A summary of the Pearson, Bennet, \& Finell (1977) report. Am J Audiol 1998;7:21--25.

19 International Organization for Standardization: Ergonomic assessment of speech communication. Part 1: Speech interference level and communication distances for persons with normal hearing capacity in direct communication (SIL method). ISO 9921-1. Geneva, ISO, 1996, pp 1--10.

20 Cantor Cutiva LC, Puglisi GE, Astolfi A, Carullo A: Four-day follow-up study on the selfreported voice condition and noise condition of teachers: relationship between vocal parameters and classroom acoustics. J Voice 2017;31:120.e1--e8.

21 Picard M, Bradley JS: Revisiting speech interference in classrooms. Audiology 2001;40:221--244.

22 Echternach M, Nusseck M, Dippold S, Spahn C, Richter B: Fundamental frequency, sound pressure level and vocal dose of a vocal loading test in comparison to a real teaching situation. Eur Arch Otorhinolaryngol 2014;271:3263--3268. 
23 Södersten M, Salomão GL, McAllister A, Ternström S: Natural voice use in patients with voice disorders and vocally healthy speakers based on 2 days voice accumulator information from a database. J Voice 2015;29:646.e1--e9.

24 Jónsdóttir V, Rantala LM, Oskarsson GK, Sala E: Effects of pedagogical ideology on the perceived loudness and noise levels in preschools. Noise Health 2015;17:282--293.

25 Pelegrin-Garcia D, Lyberg Åhlander V, Rydell R, Brunskog J, Löfqvist A: Influence of classroom acoustics on the voice levels of teachers with and without voice problems: a field study. Proc Meet Acoust 2010;11:1.

26 Skarlatos D, Manatakis M: Effects of classroom noise on students and teachers in Greece. Percept Mot Skills 2003;96:539--544.

27 Sarantopoulos G, Lykoudis S, Kassomenos P: Noise levels in primary schools of medium sized city in Greece. Sci Total Environ 2014;482-483:493--500.

28 Manlove EE, Frank T, Vernon-Feagans L: Why should we care about noise in classrooms and child care settings? Child Youth Care Forum 2001;30:55--64.

29 Crandell CC, Smaldino JJ: Classroom acoustics for children with normal hearing and with hearing impairment. Lang Speech Hear Serv Sch 2000;31:362--370.

30 Rantala LM, Sala E: Effects of classroom acoustics on teachers' voices. Build Acoust $2015 ; 22: 243--258$.

31 Shield B, Greenland E, Dockrell J: Noise in open plan classrooms in primary schools: a review. Noise Health 2010;12:225--234.

32 Kuuskorpi M, Gonzáles NC: Physical learning environments: learning in the future; in Kuuskorpi M (ed): Perspectives from Finland - towards New Learning Environments. Tampere, Finnish National Board of Education, 2014, pp 63--77.

33 Sulonen J, Sulonen K: The grammar of a modern school building. A comparative study on schools and the changing ways of learning; in Kuuskorpi M (ed): Perspectives from 
Finland - towards New Learning Environments. Tampere, Finnish National Board of Education, 2014, pp 78--101.

34 Remacle A, Finck C, Roche A, Morsomme D: Vocal impact of a prolonged reading task at two intensity levels: objective measurements and subjective self-ratings. J Voice 2012;26:e177--e186.

35 Laukkanen A, Ilomäki I, Leppänen K, Vilkman E: Acoustic measures and self-reports of vocal fatigue by female teachers. J Voice 2008;22:283--289.

36 Rantala L, Lindholm P, Vilkman E: F0 change due to voice loading under laboratory and field conditions. A pilot study. Logoped Phoniatr Vocol 1998;23:164--168.

37 Vintturi J, Alku P, Lauri E, Sala E, Sihvo M, Vilkman E: Objective analysis of vocal warmup with special reference to ergonomic factors. J Voice 2001;15:36--53.

38 Boersma P, Weenink D: Praat: Doing phonetics by computer [computer program]. 2014, Version 5.3.79. http://www.praat.org/.

39 Oliveira G, Davidson A, Holczer R, Kaplan S, Paretzky A: A comparison of the use of glottal fry in the spontaneous speech of young and middle-aged American women. J Voice 2016;30:684--687.

40 Colton RH, Casper JK, Leonard R: Understanding Voice Problems. A Physiological Perspective for Diagnosis and Treatment, ed 3. Philadelphia, Lippincot Williams \& Wilkins, 2006, pp 83, 394.

41 Lehto L, Laaksonen L, Vilkman E, Alku P: Occupational voice complaints and objective acoustic measurements -- do they correlate? Logoped Phoniatr Vocol 2006;31:147--152.

42 Verdonck-de Leeuw IM, Festen JM, Mahieu HF: Deviant vocal fold vibration as observed during videokymography: the effect on voice quality. J Voice 2001;15:313--322. 
43 Vilkman E, Lauri E, Alku P, Sala E, Sihvo M: Effects of prolonged oral reading on F0, SPL, subglottal pressure and amplitude characteristics of glottal flow waveforms. J Voice 1999;13:303--312.

44 Costa MMB, Maliska C: A new hypothesis for fluidification of vocal-fold mucus: scintigraphic study. J Voice 2012;26:276--279.

45 Bonilha HS, White L, Kuckhahn K, Gerlach TT, Deliyski DD: Vocal fold mucus aggregation in persons with voice disorders. J Commun Disord 2012;45:304--311.

Fig. 1. The portable voice accumulator (VoxLog, Sonvox AB, Sweden) consists of a neck collar with a built-in microphone and an accelerometer and of a small accumulation unit (11.5 $\times$ $8 \times 2 \mathrm{~cm})$.

Fig. 2. a The medians (Md) and maxima (Max) of the activity noise level measurements of each teacher during the first and the last lessons in core subjects in group 1 (a) and group 2 (b).

Fig. 3. Differences in the activity noise levels from the first to the last lessons in core subjects ( $n$ $=24)$. 
Table 1. Distributions of participants' voice symptoms and need for sick leave $(n=24)$

\begin{tabular}{|c|c|c|c|c|}
\hline Symptom & Seldom $^{1}$ & Occasionally $^{2}$ & Quite often ${ }^{3}$ & Very often ${ }^{4}$ \\
\hline My voice gets tired after a long period of talking & $0(-)$ & $3(13)$ & $17(71)$ & $4(17)$ \\
\hline My voice is hoarse without infection & $0(-)$ & $9(38)$ & $10(42)$ & $5(21)$ \\
\hline I feel a lump in my throat & $4(17)$ & $13(54)$ & $5(21)$ & $2(8)$ \\
\hline I feel irritating mucus in my throat & $2(8)$ & $8(33)$ & $9(38)$ & $5(21)$ \\
\hline When I talk a lot, my throat hurts & $6(25)$ & $4(17)$ & $12(50)$ & $2(8)$ \\
\hline My throat feels dry after a long period of talking & $1(4)$ & $6(25)$ & $11(46)$ & $6(25)$ \\
\hline My voice does not penetrate the noise & $9(38)$ & $8(33)$ & $5(21)$ & $2(8)$ \\
\hline I have voice breaks when talking ${ }^{5}$ & $6(25)$ & $10(42)$ & $6(25)$ & $1(4)$ \\
\hline I have had aphonia without infection & $14(58)$ & 7 (29) & $2(8)$ & $1(4)$ \\
\hline I have had sick leaves due to voice problems & $15(63)$ & $9(38)$ & $0(-)$ & $0(-)$ \\
\hline
\end{tabular}

Values represent $n(\%) .{ }^{1}$ Less seldom than once a year or never. ${ }^{2}$ A couple of times a year or occasionally. ${ }^{3}$ About once a month or quite often. ${ }^{4}$ Almost every week or very often. ${ }^{5}$ One of the teachers did not answer this question. 
Table 2. Activity noise levels and voice SPL of group $1(n=18)$ and group $2(n=6)$

\begin{tabular}{|c|c|c|c|c|c|c|}
\hline & \multicolumn{3}{|c|}{$\begin{array}{l}\text { First lesson in a core } \\
\text { subject }\end{array}$} & \multicolumn{3}{|c|}{$\begin{array}{l}\text { Last lesson in a core } \\
\text { subject }\end{array}$} \\
\hline & Md & $\begin{array}{l}\min - \\
\max \end{array}$ & $\begin{array}{l}\text { Q1, } \\
\text { Q3 }\end{array}$ & $\mathrm{Md}$ & $\begin{array}{l}\min - \\
\max \end{array}$ & Q1, Q3 \\
\hline \multicolumn{7}{|c|}{ Activity noise levels } \\
\hline Group 1 & $78 \mathrm{~dB}$ & $70-85$ & 73,81 & $78 \mathrm{~dB}$ & $74-84$ & 78,80 \\
\hline Group 2 & $60 \mathrm{dBA}$ & $55-71$ & 56,70 & $63 \mathrm{dBA}$ & $58-67$ & 59,66 \\
\hline \multicolumn{7}{|c|}{ Voice SPL at $0.1 \mathrm{~m}$} \\
\hline Group 1 & $82 \mathrm{~dB}$ & $76-88$ & 77,84 & $81 \mathrm{~dB}$ & $76-88$ & 80,87 \\
\hline Group 2 & $85 \mathrm{dBA}$ & $82-88$ & 82,87 & $86 \mathrm{dBA}$ & $81-88$ & 83,87 \\
\hline
\end{tabular}


fpl484204_f01.jpg

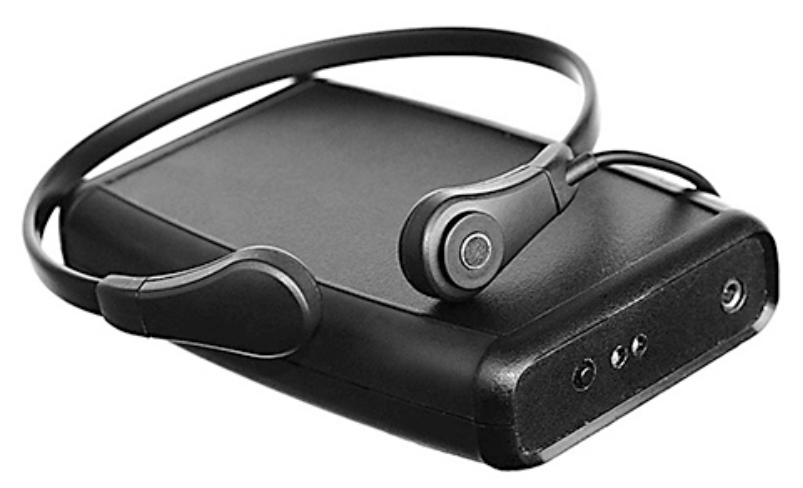


FPL484204_F02_1.jpg

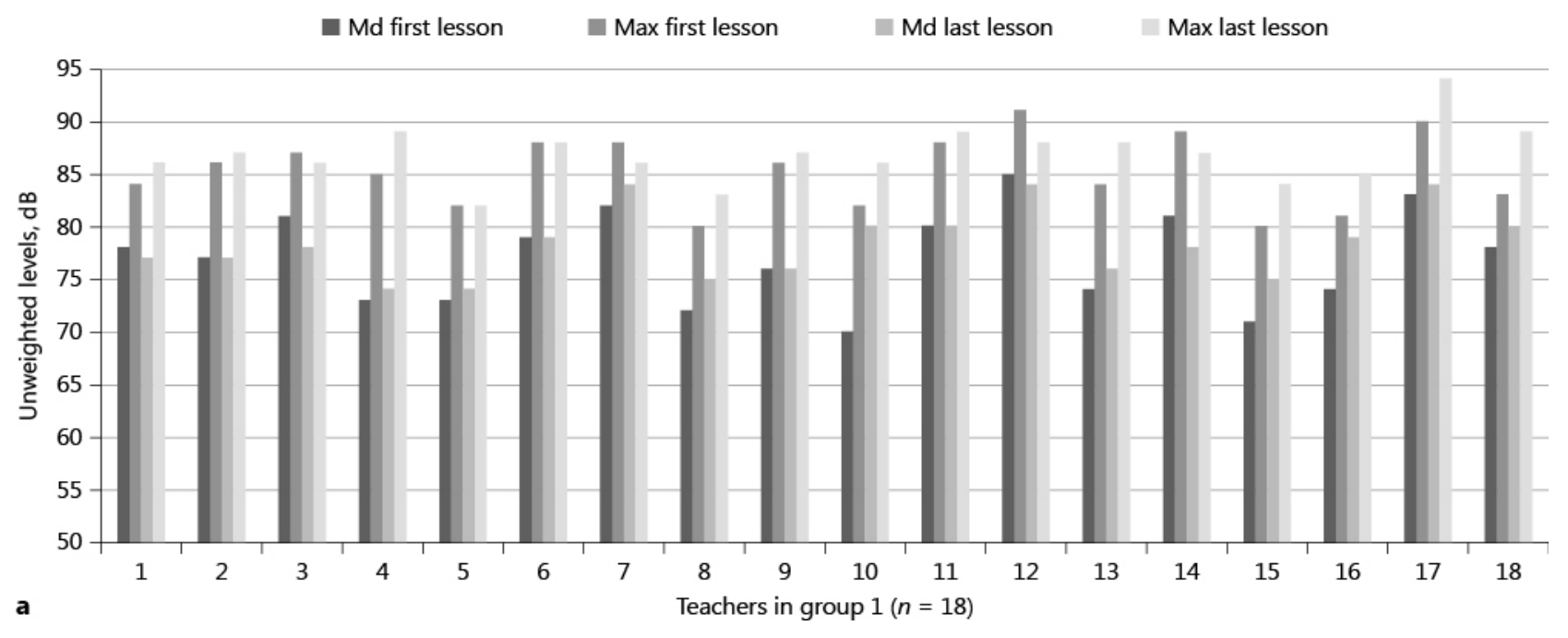




\section{FPL484204_F02_2.jpg}

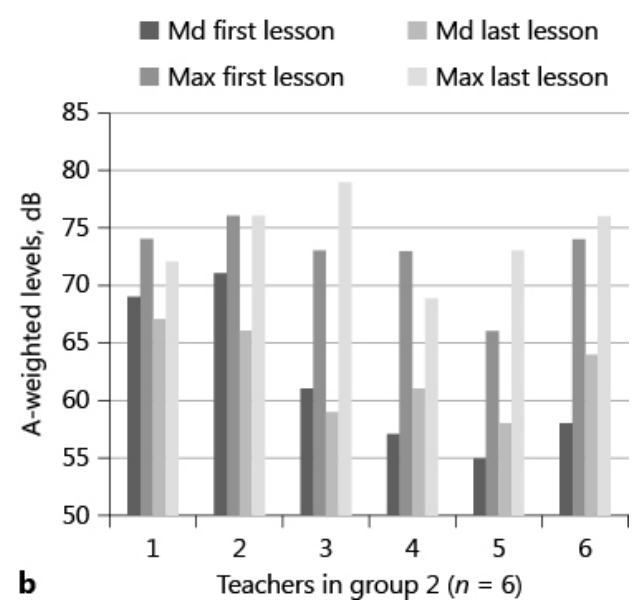




\section{FPL484204_F03.jpg}

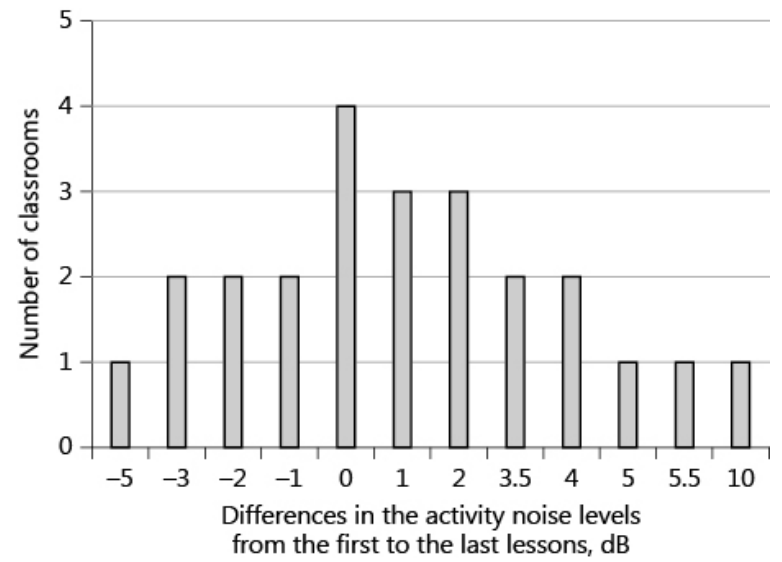

